\title{
Genetic Diversity and Phylogeny of the Genus Euplotes (Protozoa, Ciliophora) Revealed by the Mitochondrial CO1 and Nuclear Ribosomal Genes
}

\author{
Congcong Wang ${ }^{1}$, Yue $\mathrm{Hu}^{2}$, Alan Warren ${ }^{3}$ and Xiaozhong $\mathrm{Hu}^{1 \text {,* }}$ \\ 1 Key Laboratory of Mariculture, Ministry of Education, College of Fisheries, Ocean University of China, \\ Qingdao 266003, China; wangcocoh@163.com \\ 2 Oxford Sixth Form College, Oxford OX1 4HT, UK; yue.hu@oxfordsixthformcollege.com \\ 3 Department of Life Sciences, Natural History Museum, London SW7 5BD, UK; a.warren@nhm.ac.uk \\ * Correspondence: xiaozhonghu@ouc.edu.cn; Tel.: +86-532-8203-1610
}

check for updates

Citation: Wang, C.; Hu, Y.; Warren, A.; $\mathrm{Hu}, \mathrm{X}$. Genetic Diversity and Phylogeny of the Genus Euplotes (Protozoa, Ciliophora) Revealed by the Mitochondrial CO1 and Nuclear Ribosomal Genes. Microorganisms 2021, 9, 2204. https://doi.org/ 10.3390/microorganisms 9112204

Academic Editor:

Johannes Wöstemeyer

Received: 8 September 2021

Accepted: 19 October 2021

Published: 22 October 2021

Publisher's Note: MDPI stays neutral with regard to jurisdictional claims in published maps and institutional affiliations.

Copyright: (c) 2021 by the authors. Licensee MDPI, Basel, Switzerland. This article is an open access article distributed under the terms and conditions of the Creative Commons Attribution (CC BY) license (https:/ / creativecommons.org/licenses/by/ $4.0 /)$.

\begin{abstract}
Nuclear ribosomal and mitochondrial genes have been utilized individually or in combination to identify known species and discriminate closely related species. However, compared with metazoans, genetic diversity within the ciliate order Euplotida is poorly known. The aim of this study is to investigate how much nucleotide sequence divergence occurs within Euplotes. A total of 14 new gene sequences, comprising four SSU rDNA and 10 CO1 (including three species for the first time) were obtained. Phylogenetic analyses were carried out based on sequences of two DNA fragments from the same 27 isolates. We found that CO1 revealed a larger interspecific divergence than the SSU rRNA gene, thus demonstrating a higher resolution for separating congeners. Genetic distances differ significantly at the species level. Euplotes balteatus was revealed to have a large intraspecific variation at two loci, while E. vannus showed different levels of haplotype variability, which appeared as a polyphyletic cluster on the $\mathrm{CO} 1$ tree. These high genetic divergences suggest the presence of more cryptic species. By contrast, the $\mathrm{CO} 1$ gene showed low variability within E. raikovi, appearing as monophyletic clusters, which indicates that this species could be identified based on this gene. Conclusively, CO1 is a suitable marker for the study of genetic diversity within Euplotes, and increased taxon sampling gives an opportunity to screen relationships among members of this genus. Additionally, current data present no clear biogeographical pattern for Euplotes.
\end{abstract}

Keywords: ciliate; CO1 gene; genetic diversity; microeukaryote; molecular phylogeny; SSU rDNA

\section{Introduction}

Traditional taxonomy of protozoans relies heavily on high expertise. Numerous studies have suggested a higher protozoan diversity than originally proposed [1], which brings a great challenge for taxonomy. Therefore, it is critical to seek technical assistance for the initial description and subsequent recognition of organisms [2]. Though a gene-based identification system can aid the resolution of an organism's diversity, the identification and determination of the systematic position of a species using genetic information is still a tempting target. Ciliates (phylum Ciliophora), as a diverse group of protozoans, have a wide geographical distribution and play a vital ecological role as trophic links in microbial food webs [3-5]. Despite this significance, our knowledge of ciliate genetic diversity is neither complete nor equal across the entire phylum, especially when compared with the huge amount of morphological information. To date, a variety of molecular methods (e.g., DNA-DNA hybridization, gene sequencing, and RAPD fingerprinting) have been used to assess genetic variation at different taxonomic levels [3,6,7]. Among these, comparisons of nuclear small-subunit ribosomal RNA gene (SSU rDNA) sequences are commonly applied [8-14]. However, recent studies have shown the limitations of SSU rDNA for discriminating closely related congeners [15-18]. Another genetic marker is, therefore, needed. 
Compared with nuclear DNA, the evolution of the cytochrome $c$ oxidase subunit I (CO1) gene is fast enough to allow the discrimination of not only closely related organisms, but also phylogeographic groups within a single species [19]. Folmer et al. (1994) [20] conducted a pilot study to design "universal" DNA primers for a polymerase chain reaction (PCR) amplification of the CO1 gene in 11 metazoan invertebrate phyla. Thereafter, $\mathrm{CO} 1$ sequence divergences have been used to discriminate closely related species in all animal phyla except the Cnidaria [21-23]. However, attempts to use mitochondrial gene sequences to study intraspecific variation, discriminate morphospecies, or reveal phylogenetic relationships among ciliates have been restricted to relatively few taxa, e.g., Frontonia, Paramecium, Tetrahymena, Carchesium polypinum, and Miamiensis avidus [24-34]. This could be attributed to the general disadvantage of rapidly evolving markers, i.e., primer design can be elaborate and, once developed, applications of the primers are often restricted to one species only. Fortunately, a few available primer sets show great potential for the amplification of more variable DNA fragments, e.g., CO1 and ITS1-5.8S-ITS2-5'LSU rDNA, in certain species belonging to classes Oligohymenophorea and Spirotrichea $[24,30,35,36]$.

Ciliates show a wide distribution with members present in various biotopes such as freshwater, brackish water, marine, and terrestrial environments, from the tropics to polar regions [37-44]. However, due to the imbalance of regional research and insufficient sampling, little is known about the geographical distribution pattern and genetic diversity. Nowadays, it is well known that sequencing technology can provide rich data, which is conducive to the study of ciliates biogeography and population genetics [45]. Euplotes may be one of the best studied ciliate genera from a morphological perspective. Furthermore, as a speciose genus, Euplotes includes more than 100 nominal species [38,46-48], which provides a good opportunity to study sequence variation at the genus and species level and to explore the availability and utility of molecular markers.

Traditionally, Euplotes species have been identified based on their biotope, living morphology, ciliary pattern, and silver-line system. Nuclear ribosomal gene sequences, especially SSU rDNA, have also been widely used in phylogenetic analysis [46-50]. By contrast, there is only one report that includes information on the genetic divergence of the CO1 gene in Euplotes, i.e., Park et al. [35], who obtained the CO1 sequences of 47 spirotrichs, including five identified Euplotes species, and analyzed the intraspecific variation in two of these. Furthermore, previous studies have demonstrated that phylogenetic analyses based on a single gene marker may give biased results and recommended that at least two loci should be used $[18,46,51]$. Therefore, in the present study we applied two loci (SSU rDNA and CO1 DNA) to shed some light on intraspecific relationships among certain Euplotes species.

In order to reduce error rates caused by misidentification, we used only well-outlined species in the present study. This resulted in the obtaining of ten new $\mathrm{CO} 1$ sequences and four new SSU rDNA sequences from four species. Combining other data downloaded from GenBank, we constructed a data set comprising 27 species. Comparative and phylogenetic studies were performed, the main aims of which were to: (1) investigate how much nucleotide sequence divergence occurs within Euplotes; (2) assess whether the CO1 gene can be used as a biodiversity marker.

\section{Materials and Methods}

\subsection{Ciliate Culture and Identification}

Ten Euplotes populations were collected from various habitats in China (Table 1). Morphological methods (e.g., live observation, protargol and wet silver nitrate staining) were performed to determine their species identity [52]. 
Table 1. Specifications of species with both SSU rDNA and partial CO1 gene sequence data from the same isolates analyzed in this study (new sequences in bold).

\begin{tabular}{|c|c|c|c|c|c|c|c|}
\hline \multirow{2}{*}{ Species } & \multirow{2}{*}{ Geographic Origin } & \multirow{2}{*}{ Isolate ID } & \multirow{2}{*}{ Abbreviation } & \multicolumn{2}{|c|}{ GenBank Accession Numbers } & \multirow{2}{*}{$\begin{array}{l}\mathrm{GC} \% \text { of } \\
\mathrm{CO} 1\end{array}$} & \multirow{2}{*}{$\underset{\text { SSU }}{\mathrm{GC} \% \text { of }}$} \\
\hline & & & & $\mathrm{CO} 1$ & SSU & & \\
\hline Euplotes antarcticus & King George Island, Antarctic & INHC065 & Ea & MG594912 & MG603602 & $39.54 \%$ & $43.59 \%$ \\
\hline Euplotes cristatus & Incheon, South Korea & KS008 & Ecr & MG594913 & GU953667 & $41.00 \%$ & $43.75 \%$ \\
\hline Euplotes indica & Raj Ghatpond, India & OBS2 & $\mathrm{Ei}$ & MN243924 & MN038061 & $32.53 \%$ & $43.50 \%$ \\
\hline Euplotes lynni & the Sanjay Lake, India & SLS1 & $\mathrm{El}$ & MN027507 & MG827339 & $37.16 \%$ & $43.90 \%$ \\
\hline Euplotes vannus & Incheon, South Korea & KS106 & Ev1 & MG594914 & MG603630 & $36.82 \%$ & $43.85 \%$ \\
\hline Euplotes vannus & Incheon, South Korea & KS107 & Ev2 & MG594915 & MG603631 & $36.61 \%$ & $43.87 \%$ \\
\hline Euplotes vannus & Jeju-do Island, South Korea & KS012 & Ev3 & MG594916 & MG603635 & $35.77 \%$ & $43.83 \%$ \\
\hline Euplotes vannus & East River, New York, USA & WS052 & Ev4 & MG594917 & MG603648 & $36.36 \%$ & $43.85 \%$ \\
\hline Euplotes vannus & Incheon, South Korea & KS006 & Ev5 & MG594918 & MG603640 & $37.45 \%$ & $43.85 \%$ \\
\hline Euplotes vannus & Incheon, South Korea & KS074 & Ev6 & MG594919 & MG603641 & $38.08 \%$ & $43.85 \%$ \\
\hline Euplotes vannus & Incheon, South Korea & KS109 & Ev7 & MG594920 & MG603632 & $37.66 \%$ & $43.85 \%$ \\
\hline Euplotes vannus & Qingdao, China & A764 & Ev8 & MW811176 & KX302698 & $34.10 \%$ & $43.38 \%$ \\
\hline Euplotes vannus & Qingdao, China & A940 & Ev9 & MZ505008 & MZ477200 & $34.73 \%$ & $43.91 \%$ \\
\hline Euplotes vannus & Qingdao, China & A844 & Ev10 & MZ505007 & MZ477199 & $34.73 \%$ & $44.20 \%$ \\
\hline Euplotes vannus & Shenzhen, China & C102 & Ev11 & MZ505009 & MZ477201 & $34.38 \%$ & $43.78 \%$ \\
\hline Euplotes woodruffi & $\begin{array}{l}\text { Songjiho Lagoon, Gangwon-do, } \\
\text { South Korea }\end{array}$ & KS056 & Ew & MG594921 & MG603639 & $33.68 \%$ & $44.81 \%$ \\
\hline Euplotes minuta & Jeju-do Island, South Korea & KS011 & Em1 & MG594907 & MG603633 & $41.21 \%$ & $43.61 \%$ \\
\hline Euplotes minuta & Busan, South Korea & KS044 & Em2 & MG594908 & MG603638 & $41.21 \%$ & $43.61 \%$ \\
\hline Euplotes minuta & Laguna Beach, California, USA & WS038 & Em3 & MG594909 & MG603645 & $41.21 \%$ & $43.61 \%$ \\
\hline Euplotes minuta & Laguna Beach, California, USA & WS039 & Em4 & MG594910 & MG603646 & $41.21 \%$ & $43.61 \%$ \\
\hline Euplotes minuta & $\begin{array}{l}\text { Chungcheongnam-do, } \\
\text { South Korea }\end{array}$ & KS082 & Em5 & MG594911 & MG603642 & $39.33 \%$ & $43.61 \%$ \\
\hline Euplotes raikovi & Zhanjiang, China & B255 & Er1 & MW811177 & KX516720 & $32.85 \%$ & $46.15 \%$ \\
\hline Euplotes raikovi & Qingdao, China & A714 & Er2 & MZ505005 & MN783334 & $32.64 \%$ & $45.51 \%$ \\
\hline Euplotes raikovi & Adriatic Coast, Italy & A841 & Er3 & MZ505006 & MZ477198 & $32.64 \%$ & $45.81 \%$ \\
\hline Euplotes balteatus & Hong Kong, China & B220 & Eb1 & MZ505004 & KX516698 & $34.73 \%$ & $44.85 \%$ \\
\hline Euplotes balteatus & Daya Bay, Huizhou, China & $\mathrm{L} 20$ & $\mathrm{~Eb} 2$ & MW811181 & KX516667 & $34.31 \%$ & $45.79 \%$ \\
\hline Euplotes neapolitanus & Shenzhen, China & L10 & En & MW811179 & FJ998024 & $30.13 \%$ & $43.31 \%$ \\
\hline
\end{tabular}

\subsection{DNA Extraction}

A single, live cell of each population was isolated under a stereomicroscope, washed five times in sterilized ambient water, and transferred to $1.5 \mathrm{ml}$ microcentrifuge tubes. Genomic DNA was then extracted using a DNeasy Blood and Tissue Kit (Qiagen, Hilden, Germany) following the manufacturer's instructions.

\subsection{Amplification and Sequencing}

Amplification of the SSU rRNA and CO1 genes were performed with primer sets according to [53] and [35], respectively, i.e., 18SF: 5'-AACCTGGTTGATCCTGCCAGT-3'; 18SR: 5'- TGATCCTTCTGCAGGTTCACCTAC-3'; CiCO1 Fv2: 5'-GWT GRG CKA TGA TYA CAC C-3'; CiCO1 Rv2: 5'-ACC ATR TAC ATA TGA TGW CC-3'. The PCR amplifications were performed using Q5 Hot Start High-Fidelity 2x Master Mix DNA Polymerase (NEB, Ipswich, MA) with the following protocol: one cycle of initial denaturation at $98^{\circ} \mathrm{C}$ for $30 \mathrm{~s}$, followed by 18 cycles of amplification $\left(98^{\circ} \mathrm{C}, 10 \mathrm{~s} ; 69^{\circ} \mathrm{C}-51{ }^{\circ} \mathrm{C}\right.$ touch down, $\left.30 \mathrm{~s} ; 72{ }^{\circ} \mathrm{C}, 1 \mathrm{~min}(\mathrm{CO} 1,30 \mathrm{~s})\right)$ and another 18 cycles $\left(98{ }^{\circ} \mathrm{C}, 10 \mathrm{~s} ; 51{ }^{\circ} \mathrm{C}, 30 \mathrm{~s} ; 72{ }^{\circ} \mathrm{C}, 1 \mathrm{~min}\right.$ $(\mathrm{CO} 1,30 \mathrm{~s})$ ), with a final extension of $72^{\circ} \mathrm{C}$ for $5 \mathrm{~min}$. The PCR products were detected using agarose gel and then sequenced bidirectionally by the Tsingke Biological Technology Company (Qingdao, China). Contigs were assembled by Seqman (lasergene DNAStar). 


\subsection{Sequence and Pairwise Genetic Distances Analyses}

All new nucleotide sequences have been submitted to the GenBank. Sequences of SSU and CO1 gene were aligned with the GUIDANCE2 algorithm (http:/ / guidance.tau.ac.il/ ver2/; 10 August 2021), and BioEdit 7.0 [54] was used to manually modify the resulting alignment by trimming both ends, leaving a consensus matrix of 1865 nucleotide positions (SSU rDNA) and $478 \mathrm{bp}$ (CO1 gene). Pairwise genetic distance results were also obtained by BioEdit 7.0. Analysis of haplotype diversity and its sampling variance (SD), nucleotide diversity, and variable nucleotide positions was done with DnaSP v5.10.01 [55].

\subsection{Phylogenetic Analyses}

To infer the phylogenetic position of the four Euplotes species, 99 gene sequences retrieved from the GenBank database, including 19 mitochondrial CO1 sequences (Caryotricha marina and Diophrys scutum, as outgroups) and 80 SSU rDNA sequences (Caryotricha marina and Diophrys scutum as outgroups), and the 14 new sequences obtained in this study, were used. The final alignment used for phylogenetic analyses included 2033 sites for SSU rDNA of 52 species; 1865 sites for SSU rDNA of ten species with CO1 sequences available from the same isolates; and 478 sites for $\mathrm{CO} 1$ gene of ten species. A maximum likelihood (ML) analysis with 1000 bootstrap replicates was performed on the CIPRES Science Gateway, applying the GTRGAMMA model [56] using RAxML-HPC2 on XSEDE 8.2.12 [57]. A Bayesian inference (BI) analysis was carried out with MrBayes on XSEDE 3.2.7a [58] on the CIPRES Science Gateway using the model GTR+I+G, selected by AIC in MrModeltest 2.2 [59]. Markov chain Monte Carlo (MCMC) simulations were run for 1,000,000 generations with sampling every 100 generations and a burn-in of 1000 trees. MEGA 5 [60] was used to visualize the tree topologies.

\section{Results}

Sequences of the nuclear SSU rDNA and CO1 fragments were newly obtained from10 isolates of the Euplotes species (see Table 1 for accession numbers). All positions containing gaps and missing data were eliminated.

\subsection{SSU rDNA Sequence Analysis}

The SSU rDNA sequences of ten populations (Ev8-11, Er1-3, Eb1-2, En) were between 1480 and 1905 nucleotides long, and GC content was in the range of $43.31-46.15 \%$ ( $44.67 \pm 1.08 \%)$; the mean interspecific sequence divergence was $15.83 \%$ and ranged from 7.7-29.1\% (Table S1). The SSU rDNA sequences of all 27 populations assigned to the ten species were analyzed here. Among the 282 species pairs, more than half (ca. 63.5\%) showed greater than $8 \%$ sequence divergence (Figure 1; Table 2). Within Euplotes vannus, almost all sequences were identical except for that of isolate A764, which was separated by ca. $19 \%$ divergence. The mean sequence variation within $E$. vannus was $3.73 \%$, which was significantly higher than those in Euplotes raikovi (ca. $0.93 \%$ ) and E. minuta (0.13\%). By contrast, the two populations of Euplotes balteatus had 8.3\% gene divergence (Table S1). The intraspecific haplotype diversity value was $\mathrm{Hd}=0.618(\mathrm{SD}=0.164)$ in $E$. vannus, which was similar to those of E. minuta and E. raikovi (Table 3). In contrast, every studied isolate had its own haplotype in E. balteatus. Both E. minuta and E. raikovi showed very low levels of nucleotide diversity (less than 0.0005 ; Table 3). The 11 populations of Euplotes vannus can be divided into four groups, with low intragroup diversity (less than 1\%) but high intergroup divergence (up to $18.9 \%$ ). 


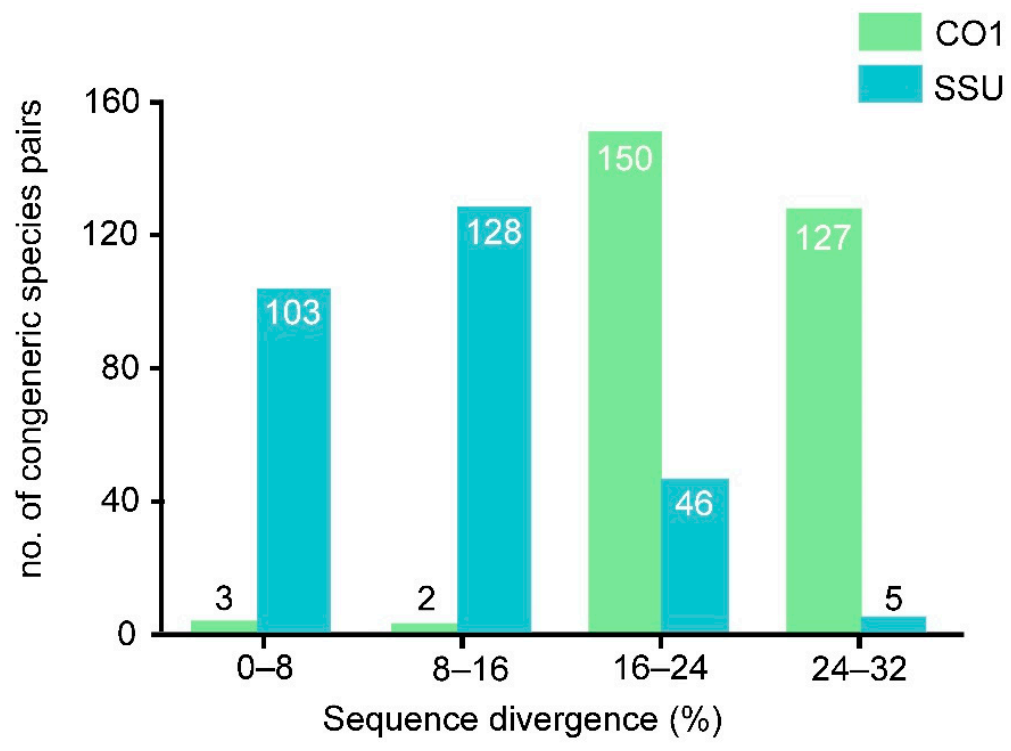

Figure 1. SSU rDNA and CO1 sequence divergences for 282 congeneric pairs of Euplotes species.

Table 2. Mean and standard deviation (s.d.) of the percentage sequence divergences of CO1 or SSU rRNA genes for congeneric species pairs within three genera. (The percentage of sequence divergence estimates falling in a particular range is also shown. $n$ indicates the number of congeneric pairs examined in each genus).

\begin{tabular}{|c|c|c|c|c|c|c|c|c|}
\hline \multirow{2}{*}{ Genus } & \multirow{2}{*}{ Gene } & \multirow{2}{*}{$\mathbf{n}$} & \multirow{2}{*}{ Mean } & \multirow{2}{*}{ s.d. } & \multicolumn{4}{|c|}{ Sequence Divergence (\%) } \\
\hline & & & & & $0-8$ & $8-16$ & $16-24$ & $24-32$ \\
\hline \multirow{2}{*}{ Euplotes } & $\mathrm{CO} 1$ & 282 & 23.1 & 3.4 & $1.1 \%$ & $0.7 \%$ & $53.2 \%$ & $45.0 \%$ \\
\hline & SSU & 282 & 10.6 & 5.7 & $36.5 \%$ & $45.4 \%$ & $16.3 \%$ & $1.8 \%$ \\
\hline Diophrys & $\mathrm{CO} 1$ & 21 & 18.8 & 0.4 & 0 & 0 & $100.0 \%$ & 0 \\
\hline Uronychia & $\mathrm{CO} 1$ & 1 & $\mathrm{n} / \mathrm{a}$ & $\mathrm{n} / \mathrm{a}$ & 0 & 0 & $100.0 \%$ & 0 \\
\hline
\end{tabular}

Table 3. Variability of the SSU rDNA and CO1 fragments in four species of Euplotes with more than two isolates each.

\begin{tabular}{|c|c|c|c|c|c|c|c|c|}
\hline \multirow[t]{2}{*}{ Species } & \multicolumn{4}{|c|}{ SSU rDNA } & \multicolumn{4}{|c|}{ CO1 mtDNA } \\
\hline & $\begin{array}{l}\text { Number of } \\
\text { Sequences }\end{array}$ & $\begin{array}{l}\text { Number of } \\
\text { Haplotypes }\end{array}$ & $\begin{array}{c}\text { Haplotype } \\
\text { Diversity (SD) }\end{array}$ & $\begin{array}{c}\text { Nucleotide } \\
\text { Diversity }\end{array}$ & $\begin{array}{l}\text { Number of } \\
\text { Sequences }\end{array}$ & $\begin{array}{l}\text { Number of } \\
\text { Haplotypes }\end{array}$ & $\begin{array}{c}\text { Haplotype } \\
\text { Diversity (SD) }\end{array}$ & $\begin{array}{l}\text { Nucleotide } \\
\text { Diversity }\end{array}$ \\
\hline Euplotes vannus & 11 & 5 & $0.618(0.164)$ & 0.00177 & 11 & 10 & $0.982(0.046)$ & 0.13551 \\
\hline Euplotes minuta & 5 & 3 & $0.700(0.218)$ & 0.00044 & 5 & 2 & $0.400(0.237)$ & 0.02176 \\
\hline Euplotes raikovi & 3 & 2 & $0.667(0.314)$ & 0.00038 & 3 & 2 & $0.667(0.314)$ & 0.00976 \\
\hline Euplotes balteatus & 2 & 2 & $1.000(0.500)$ & 0.05039 & 2 & 2 & $1.000(0.500)$ & 0.22803 \\
\hline
\end{tabular}

\subsection{CO1 Sequence Analysis}

A portion of $478 \mathrm{bp}$ from the mitochondrial $\mathrm{CO} 1$ gene of the ten species was used for the sequence analyses. The GC content was in the range of $30.13-41.21 \%(36.37 \pm 3.1 \%$; Table 1) based on 27 sequences including the ten new ones. Within Euplotes, CO1 sequence divergence among 282 species pairs ranged from a low of $0.0 \%$ to a high of $30.0 \%$ (Table S1), with a mean interspecific divergence of $23.1 \%$, and $98.2 \%$ of species pairs showing greater than $16 \%$ sequence divergence (Figure 1, Table 2). Within Euplotes vannus, the mean sequence divergence was $13.7 \%$ and ranged from 0-21.4\%. Euplotes minuta and Euplotes raikovi had a mean intraspecific divergence of $2.2 \%$ and $1 \%$, respectively, and ranged from $0-5.5 \%$. Euplotes balteatus showed a high level of intraspecific divergence $(22.9 \%)$. The haplotype diversity value of Euplotes minuta was $\mathrm{Hd}=0.4(\mathrm{SD}=0.237)$, the lowest in the four studied species. In contrast, almost every studied strain had its own haplotype in E. vannus and E. balteatus, the latter revealing the highest level of nucleotide diversity (Table 3). Euplotes vannus contained five groups with low intragroup diversity (less than $3 \%$ ) but high intergroup divergence (ranging from $9.0 \%$ to $21.2 \%$ ). 


\subsection{Phylogenetic Analysis Based on Comparison of SSU rDNA Sequences}

The phylogenetic trees constructed using two different methods (ML and BI) showed a similar topological structure, hence only ML trees are presented here.

The phylogenetic trees, based on a comparison of the SSU rDNA fragments (Figure 2) and constructed for 82 Euplotes populations (with Diophrys scutum and Caryotricha marina as outgroup), revealed the monophyly of the genus Euplotes as all 52 species for which sequence data are available grouped together with maximum support. The genus was divided into nine clades (marked on the tree as R1 to R9). Euplotes rariseta appeared as a separate branch (R9), while the other isolates from different species formed eight clades on both trees. Among these clades, R1-5 were formed by five or more species each. Isolates belonging to E. vannus, E. raikovi, and E. nobilii formed monophyletic clusters for each species within the clades, while isolates of E. blateatus were distributed among two distinct clades (R3 and R5). The cluster of E. vannus grouped with E. cristatus, E. minuta, and E. antarcticus, forming a well-supported subclade (R3a). The two earliest branching clades were composed of three recently published species each.

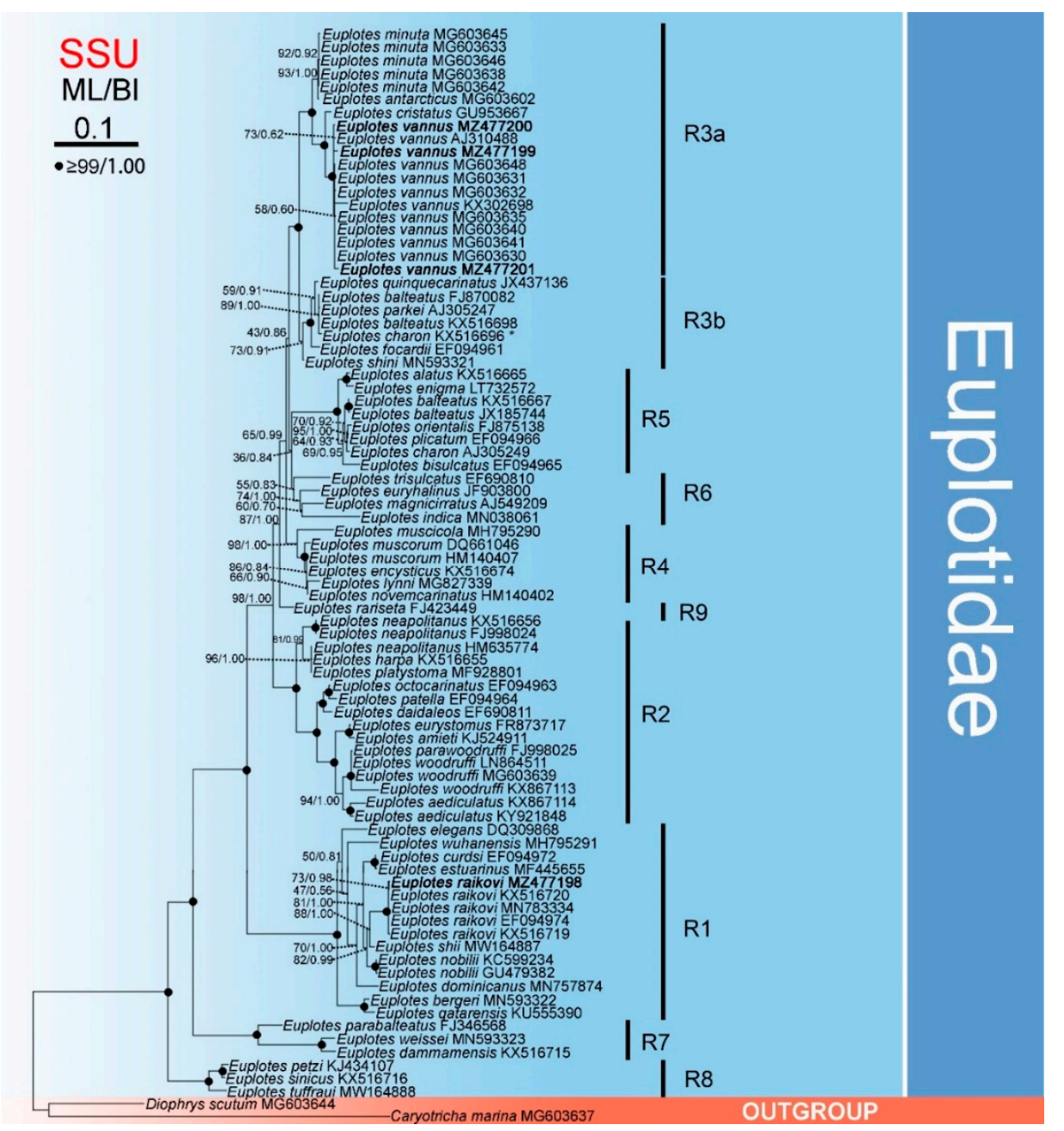

Figure 2. Maximum likelihood (ML) tree inferred from SSU rDNA sequences showing nodal support for ML and BI analyses. Newly sequenced species are shown in bold. A hyphen (-) reflects disagreement in topology between the BI and ML trees. R1-9 represent different clades. The scale bar corresponds to 10 substitutions per 100 nucleotide positions. ${ }^{*}$ misidentification, should be Euplotes balteatus.

The phylogenetic trees for the SSU rDNA fragments of only ten Euplotes species with CO1 sequences available from the same isolates (with Diophrys scutum and Caryotricha 
marina as the outgroup) had a similar topology (Figure 3) to the ribosomal tree that included all 52 species for which sequence data are available (Figure 2). The isolates of these ten Euplotes species formed six clusters (R1-6), four of which consisted of one or two species each. R3 was composed of three subclades, viz. Euplotes minuta + E. antarcticus, Euplotes vannus + E. cristatus, and the Hong Kong population of E. balteatus.

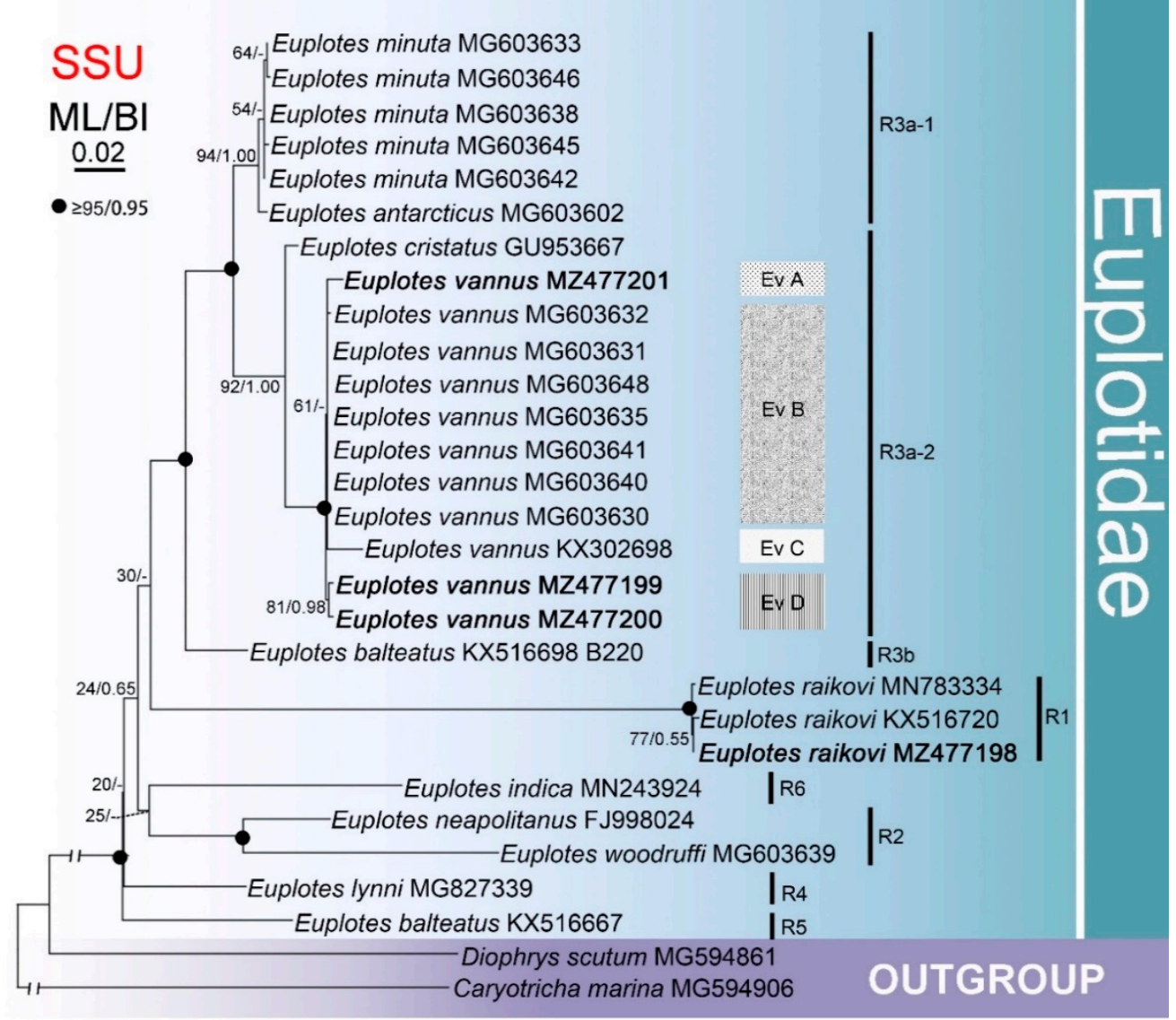

Figure 3. Maximum likelihood (ML) tree inferred from SSU rDNA sequences of 10 Euplotes species that had isolates for which CO1 sequence data are also available. Nodal support is given for both ML and BI analyses. Newly sequenced species are shown in bold. A hyphen (-) reflects disagreements in topology between the BI and ML trees. R1-6 represent different clades and Ev A-D for groups of Euplotes vannus. The scale bar corresponds to two substitutions per 100 nucleotide positions.

Although Euplotes vannus formed a well-separated cluster, the SSU rDNA tree revealed the existence of four intraspecific groups, namely Ev A, Ev B, Ev C, and Ev D, corresponding to the divergences demonstrated previously. Ev A and Ev C each contained one China isolate, viz. from the Shenzhen and Qingdao regions, respectively. Ev B was composed of five isolates from Incheon, South Korea, one from Jeju-do Island, South Korea, and one from New York, USA. Ev D consisted of two Qingdao isolates.

\subsection{Phylogenetic Analysis Based on Comparison of Partial CO1 Sequences}

The ML and BI trees based on the CO1 gene sequences of ten Euplotes species (27 isolates) had similar topologies, therefore only the ML tree is shown here (Figure 4). However, the topology of this tree is somewhat different to that of the equivalent SSU rDNA tree (Figure 3). For easier orientation, clades on the phylogenetic tree were numbered as in the SSU rDNA tree and differed only in the letter ( $\mathrm{R}$-for SSU rDNA (Figures 2 and 3), C-for CO1 (Figure 4)). In total, ten clusters were recovered (Figure 4). 


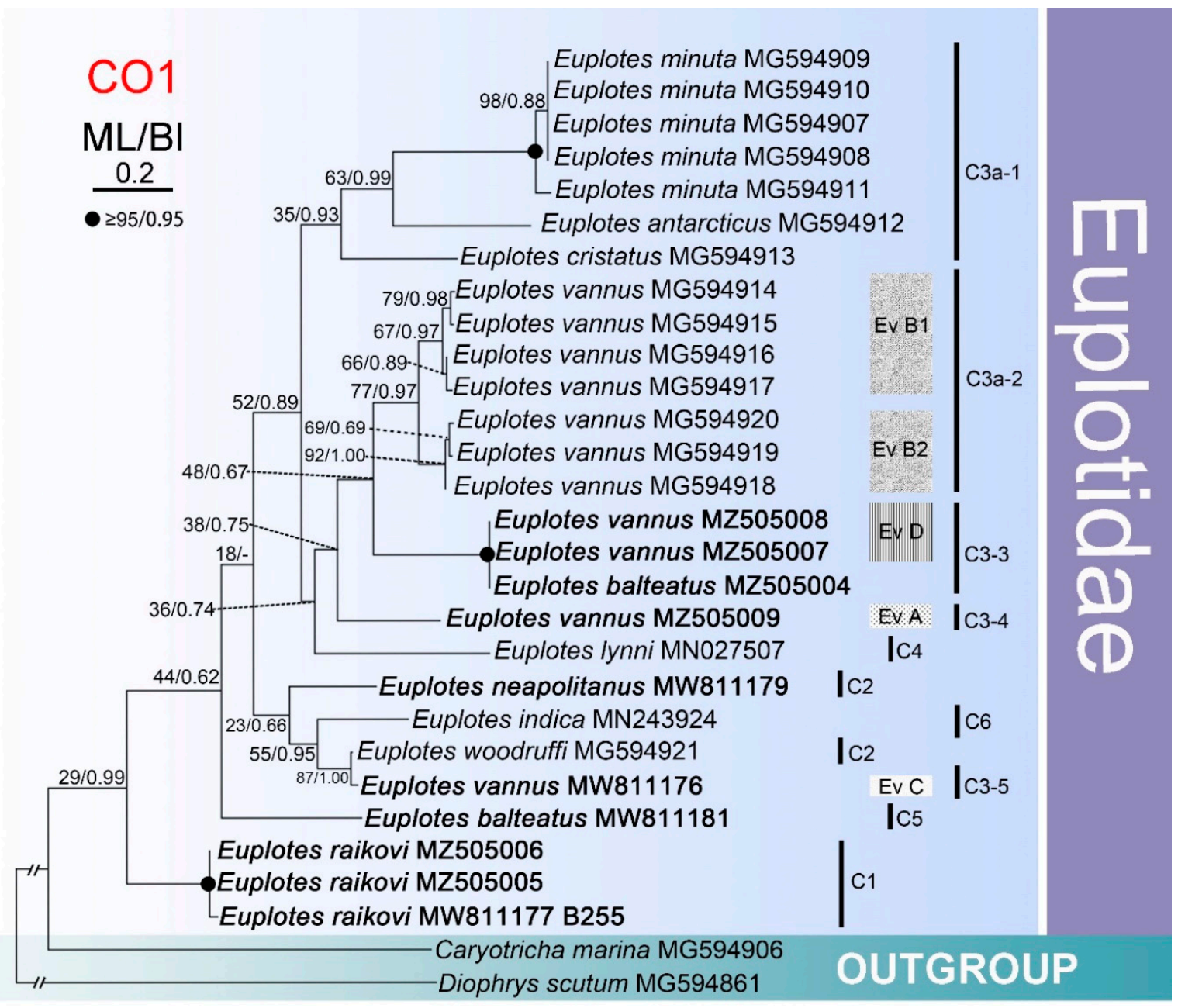

Figure 4. Maximum likelihood (ML) tree inferred from mitochondrial cytochrome $c$ oxidase subunit 1 (CO1) nucleotide sequences of ten Euplotes species showing nodal support for ML and BI analyses. Newly-sequenced species are shown in bold. Disagreements between ML and BI are shown by hyphens. C1-6 represent different clades and Ev A-D for groups of Euplotes vannus. The scale bar corresponds to 20 substitutions per 100 nucleotide positions.

Both in the ribosomal and mitochondrial trees, E. balteatus (L20) appeared as a separate branch (C5), which did not group with E. balteatus (B220). In the case of the CO1 tree, the earliest branching clade (C1) consisted of only isolates of Euplotes raikovi, which also formed a long-branched and well-supported cluster (R1) in the SSU rDNA tree. Another well-supported cluster corresponded to Euplotes minuta which showed a close relationship with E. antarcticus, as in the rDNA tree (Figures 2-4). Unlike in the SSU rDNA tree where all isolates of Euplotes vannus clustered together with maximal support, in the $\mathrm{CO} 1$ tree they were divided into five groups (Ev A, Ev B1, Ev B2, Ev C, Ev D) of which four grouped together but with weak support. Another Qingdao isolate of Euplotes vannus (A764) nested into a separate clade and had a closer relationship with E. woodruffi, a form of which is sister to E. neapolitanus in the ribosomal tree (Figure 3). It is noteworthy that two Qingdao isolates of E. vannus (A940, A844) formed a fully supported cluster with the Hong Kong isolate of E. balteatus, as they had identical sequences and were sister to a cluster formed by isolates of E. vannus from South Korea and the USA.

Other differences between the CO1 and SSU rDNA trees include the positions of particular subclades or species, e.g., E. raikovi (C1), E. neapolitanus and E. woodruffi, and E. cristatus. 


\section{Discussion}

\subsection{Genetic Variability within Euplotes in Comparison with Certain Other Genera}

In the present work, we revealed the level of genetic variability of two genomic fragments within the genus Euplotes by comparing our results with the background of several other ciliate genera (for example Paramecium, Diophrys, Pseudokeronopsis). The mean intraspecific divergences of Euplotes spp. differ greatly, ranging from $0.09 \%$ to $0.83 \%$ for SSU rDNA, and $0.1 \%$ to $22.9 \%$ for CO1, which is the greatest variability of the studied mitochondrial fragments in ciliates reported to date $[18,30-32,35]$. The mean interspecific variability for CO1 within Euplotes is generally larger than that of Diophrys and Uronychia (Tables S1 and S2), as well as some species of Paramecium [24]. At present, we cannot explain exactly why Euplotes shows such a great divergence, but one possibility is that its species differentiated earlier and underwent a relatively longer period of evolution.

Compared with the SSU rDNA data, the mitochondrial data revealed considerably higher sequence divergences within and among the investigated Euplotes species (Table 2 and Table S1). Moreover, the two studied fragments revealed intraspecific variability within Euplotes vannus, but the mitochondrial sequences showed a clearer differentiation of the isolates (Figures 2-4; Table S1).

\subsection{The Genus Euplotes Contains Both Polyphyletic and Monophyletic Species}

Based on all the Euplotes species for which SSU rDNA sequence data are available, the present analysis corroborates the monophyly of Euplotes [44,46-49,61]. Nevertheless, our findings revealed more well-supported phylogenetic clades than previous phylogenetic studies $[50,62,63]$. In part, this can be attributed to the increased taxon sampling, which improved analytic resolution and helped to recover phylogenetic relationships among related species in the ribosomal tree (Figures 2 and 3). For example, the phylogenetic positions of Euplotes raikovi, E. indica, and E. lynni remain uncertain in Figure 3, but their phylogenies were resolved in Figure 2.

Comparative analyses of two genome fragments, using 27 isolates belonging to ten species, revealed significant sequence variability and a range of degrees of intraspecific differentiation in particular species (as described above). Based on the obtained trees, E. raikovi forms a monophyletic cluster, which is consistent with its morphological classification $[37,47]$. Euplotes aediculatus and E. nobilii also form monophyletic clusters on the SSU rDNA tree as in previous studies [43]. These three species have stable morphological traits among populations, even though they have wide geographic distributions $[46,47,64]$. This congruence between morphological and genetic discrimination could be explained by the fact that they are well-differentiated species.

A few morphologically indistinguishable species do not correspond to the species boundaries determined by genetics. Although more isolates were used for the analysis in the present study, E. vannus was revealed to be monophyletic, based on the analyses of the SSU rDNA sequence data comparison, as reported previously [35]. In contrast, the CO1 analysis revealed E. vannus to be polyphyletic. Similar to a previous study [35], five strains of E. minuta formed a monophyletic cluster in the mitochondrial tree, but this was not supported in the ribosomal tree.

In contrast to the above-mentioned species, E. balteatus is polyphyletic. The genetic diversity of E. balteatus isolates has been studied twice using the ribosomal molecule [50,61], however it has never been investigated using the $\mathrm{CO} 1$ fragment. The present study revealed a significant sequence divergence between two populations in both rDNA and CO1 loci, which infers the presence of putative cryptic species, as suggested by Barth et al. [24].

\subsection{Utility of SSU rDNA and CO1 as Biodiversity Markers}

An important task for evolutionary biologists is to identify and determine the systematic positions of related taxa using information derived from their genomes. The molecular phylogeny of ciliates is mainly based on SSU rDNA sequence data, and this has helped to resolve a great number of systematic problems [6,9]. However, while some authors have 
detected higher interspecific variation using SSU rDNA [8,10-14], others have obtained no or low sequence variability between certain congeners, or even between different genera, for example, in Pseudourostyla [15], Pseudouroleptus [16], Tetrahymena [17], Pseudokeronopsis [18], Euplotes [35], and Paramecium [65]. This indicates the low resolution of SSU rDNA as a species discriminator. Therefore, another gene marker is urgently required to identify species. The mitochondrial cytochrome $c$ oxidase $1(\mathrm{CO} 1)$ gene shows a high evolutionary rate and high copy number per cell [66]. Moreover, this DNA fragment has been shown to be effective in identifying many metazoans [20-23]. These render the $\mathrm{CO} 1$ gene as a marker of choice. In the last 15 years, several attempts have been made to use mitochondrial sequences to study genetic variation in ciliates. According to these studies, mitochondrial data revealed substantially higher divergences within and between the investigated species and could also serve as a tool to study population genetics and identify species, possibly even new taxa. However, our study obtained different results for different species. The nucleotide divergence within Euplotes vannus and E. balteatus is extremely high (up to 23\%), whereas in E. raikovi it is rather low (0-1.5\%). The same pattern was also found using the SSU rDNA sequence. Based on the threshold values for species identities suggested by barcoding studies, high divergences indicate the presence of several cryptic species, though there is no single fixed threshold rate that can be applied to all ciliates [36]. Extremely low levels of divergence within species in diverse groups of organisms do not allow for the separation of populations in the same species, but enable the identification of known species $[17,35]$. Consequently, the application of the CO1 gene in ciliates should be cautious owing to the intrinsic limitations of the mtDNA due to its fast evolutionary rate, possible horizontal gene transfer, and the paucity of sequences in the $\mathrm{CO} 1$ barcode database.

\subsection{Biogeography of Certain Species within Euplotes}

Common views on the global geographic distribution of microeukaryotes can be divided into two schools. Microorganisms (including protists, bacteria, fungi, etc.) are generally considered to be globally distributed, as stated by Beijerinck (1913) [67], i.e., "everything is everywhere, but the environment selects". This can be interpreted as: microorganisms will appear wherever their biological needs are met $[45,68]$. Foissner proposed a moderate endemicity model, suggesting that specific ciliate species exist in a limited geographical range [69]. Evidence suggests that, with a large number of species reported worldwide and the improvement of molecular marker resolution, the distribution pattern of eukaryotic microorganisms appears to be both global and localized [30,70].

Morphological studies have revealed that some Euplotes species, such as E. vannus and E. minuta, are abundant and widely distributed (e.g., found in both the eastern and western coasts of the Pacific Ocean). Euplotes raikovi is also found in both the western coast of the Pacific Ocean and the Mediterranean Sea. In contrast, other species seem to be distributed only locally, e.g., E. antarcticus and E. forcardi are found only in Antarctica [35,44]. Thus, there is support for both hypotheses based on the distribution of ciliates.

The current available molecular data do not demonstrate a clear connection between geographical and genetic distances. With regard to E. vannus, there were no significant genetic differences among populations from distant localities based on SSU rDNA sequence data. In contrast, on the CO1 tree, South Korean and American populations clustered together, and the two populations (Qingdao and Shenzhen) from China branched separately. Likewise, neither E. minuta nor E. raikovi showed a geographical pattern. Isolates of E. minuta from South Korea were assigned to different groups, while four populations from the USA and South Korea had almost identical CO1 sequences (Table 1 and Table S1; Figure 4). Moreover, for E. raikovi, one Chinese population was more closely related to the Italian isolate than the other Chinese one. So far, whether or not Euplotes species show a biogeographical pattern has not yet been confirmed using genetic data. 


\section{Conclusions}

Based on the analyses of newly obtained sequences, more putative cryptic species were identified in morphologically indistinguishable species. The CO1 gene presents great potential for discriminating populations within certain Euplotes species. Additionally, increased taxon sampling may give an opportunity to screen relationships and distribution patterns among members of this genus.

Supplementary Materials: The following are available online at https:/ / www.mdpi.com/article/ 10.3390/microorganisms9112204/s1, Table S1: Pairwise genetic distances between the investigated Euplotes species, Table S2: Pairwise genetic distances and different base pairs between the investigated Diophrys and Uronychia species for the CO1 gene.

Author Contributions: X.H. conceived the study; C.W. and Y.H. processed the samples and performed gene sequencing; C.W. and X.H. identified species; C.W., Y.H., and A.W. analyzed data; C.W. wrote the manuscript; A.W. edited the English language; X.H. and A.W. revised the manuscript. All authors have read and agreed to the published version of the manuscript.

Funding: This work was financially supported by the National Natural Science Foundation of China (Project Number: 41976086).

Institutional Review Board Statement: Not applicable.

Informed Consent Statement: Not applicable.

Data Availability Statement: Sequences data are available in GenBank. The datasets used and/or analyzed during the current study are available from the corresponding author on reasonable request.

Acknowledgments: We thank Jiamei Jiang, Hongbo Pan, and Weiwei Liu for providing us with the 10 populations of the Euplotes species, and Yunyi Gao for technical help with the phylogenetic analysis.

Conflicts of Interest: The authors declare no conflict of interest.

\section{References}

1. Hausmann, K.; Hülsmann, N.; Radek, R. Protistology, 3rd ed.; E. Schweizerbart'sche Verlagsbuchhandlung: Berlin, Germany, 2003.

2. Godfray, H.C.J. Challenges for taxonomy. Nature 2002, 417, 17-19. [CrossRef] [PubMed]

3. Lynn, D.H. The Ciliated Protozoa: Characterization, Classification and Guide to the Literature, 3rd ed.; Springer: Dordrecht, Germany, 2008.

4. Sherr, E.; Sherr, B. High rates of consumption of bacteria by planktonic ciliates. Nature 1987, 325, 710-711. [CrossRef]

5. Sherr, E.; Sherr, B.; Paffenhöfer, G. Phagotrophic protozoa as food for metazoans: A "missing" trophic link in marine pelagic food webs? Mar. Microbiol. Food Webs 1986, 1, 61-80.

6. Elwood, H.J.; Olsen, G.J.; Sogin, M.L. The small-subunit ribosomal RNA gene sequences from the hypotrichous ciliates Oxytricha nova and Stylonychia pustulata. Mol. Biol. Evol. 1985, 2, 399-410. [PubMed]

7. Wang, C.; Gao, Y.; Lu, B.; Chi, Y.; Zhang, T.; El-Serehy, H.A.; Al-Farraj, S.A.; Li, L.; Song, W.; Gao, F. Large-scale phylogenomic analysis provides new insights into the phylogeny of the class Oligohymenophorea (Protista, Ciliophora) with establishment of a new subclass Urocentria nov. subcl. Mol. Phylogenet. Evol. 2021, 159, 107112. [CrossRef]

8. Chi, Y.; Chen, X.; Li, Y.; Wang, C.; Zhang, T.; Ayoub, A.; Warren, A.; Song, W.; Wang, Y. New contributions to the phylogeny of the ciliate class Heterotrichea (Protista, Ciliophora): Analyses at family-genus level and new evolutionary hypotheses. Sci. China Life Sci. 2020, 64, 606-620. [CrossRef] [PubMed]

9. Gao, F.; Huang, J.; Zhao, Y.; Li, L.; Liu, W.; Miao, M.; Zhang, Q.; Li, J.; Yi, Z.; El-Serehy, H.A.; et al. Systematic studies on ciliates (Alveolata, Ciliophora) in China: Progress and achievements based on molecular information. Eur. J. Protistol. 2017, 61, 409-423. [CrossRef]

10. Jiang, L.; Wang, C.; Zhuang, W.; Li, S.; Hu, X. Taxonomy and phylogeny of little-known Helicoprorodon multinucleatum Dragesco, 1960 (Ciliophora, Haptorida), with notes on geographical distribution and identification key to species within the genus. Eur. J. Protistol. 2021, 78, 125769. [CrossRef] [PubMed]

11. Jiang, L.; Zhuang, W.; El-Serehy, H.; Al-Farraj, S.A.; Warren, A.; Hu, X. Taxonomy and molecular phylogeny of two new species of prostomatean ciliates with establishment of Foissnerophrys gen. n. (Alveolata, Ciliophora). Front. Microbiol. 2021, 12, 686929. [CrossRef]

12. Li, S.; Zhuang, W.; Pérez-Uz, B.; Zhang, Q.; Hu, X. Two anaerobic ciliates (Ciliophora, Armophorea) from China: Morphology and SSU rDNA sequence, with report of a new species, Metopus paravestitus nov. spec. J. Eukaryot. Microbiol. 2021, 68, e12822. [CrossRef] [PubMed]

13. Wang, C.; Jiang, L.; Qu, Z.; Al-Farraj, S.A.; Warren, A.; Hu, X. Taxonomy and phylogeny of three species of Dysteria (Ciliophora, Phyllopharyngea) including the description of Dysteria ozakii nom. nov. Protist 2021, 712, 125831. [CrossRef] [PubMed] 
14. Wu, T.; Li, Y.; Lu, B.; Shen, Z.; Song, W.; Warren, A. Morphology, taxonomy and molecular phylogeny of three marine peritrich ciliates, including two new species: Zoothamnium apoarbuscula n. sp. and Z. apohentscheli n. sp. (Protozoa, Ciliophora, Peritrichia). Mar. Life. Sci. Technol. 2020, 2, 334-348. [CrossRef]

15. Jung, J.H.; Park, K.M.; Min, G.S. Morphology, morphogenesis, and molecular phylogeny of a new brackish water ciliate, Pseudourostyla cristatoides n. sp., from Songjiho lagoon on the coast of East Sea, South Korea. Zootaxa 2012, 3334, 42-54. [CrossRef]

16. Jung, J.H.; Park, K.M.; Min, G.S. Morphology and molecular phylogeny of Pseudouroleptus jejuensis nov. spec., a new soil ciliate (Ciliophora, Spirotrichea) from South Korea. Acta Protozool. 2014, 53, 195-206.

17. Lynn, D.H.; Strüder-Kypke, M.C. Species of Tetrahymena identical by small subunit rRNA. gene sequences are discriminated by mitochondrial cytochrome c oxidase I gene sequences. J. Eukaryot. Microbiol. 2006, 53, 385-387. [CrossRef] [PubMed]

18. Yi, Z.; Chen, Z.; Warren, A.; Roberts, D.; Al-Rasheid, K.A.S.; Miao, M.; Gao, S.; Shao, C.; Song, W. Molecular phylogeny of Pseudokeronopsis (Protozoa, Ciliophora, Urostylida), with reconsideration of three closely related species at inter- and intra-specific levels inferred from the small subunit ribosomal RNA gene and the ITS1-5.8 S-ITS2 region sequences. J. Zool. 2008, 275, 268-275.

19. Cox, A.J.; Hebert, P.D.N. Colonization, extinction and phylogeographic patterning in a freshwater crustacean. Mol. Ecol. 2001, 10,371-386. [CrossRef] [PubMed]

20. Folmer, O.; Black, M.; Hoeh, W.; Lutz, R.; Vrijenhoek, R. DNA primers for amplification of mitochondrial cytochrome c oxidase subunit I from diverse metazoan invertebrates. Mol. Mar. Biol. Biotech. 1994, 3, 294-299.

21. Hajibabaei, M.; Janzen, D.H.; Burns, J.M.; Hallwachs, W.; Hebert, P.D.N. DNA barcodes distinguish species of tropical Lepidoptera. Proc. Natl. Acad. Sci. USA 2006, 103, 968-971. [CrossRef] [PubMed]

22. Hebert, P.D.N.; Ratnasingham, S.; de Waard, J.R. Barcoding animal life: Cytochrome c oxidase subunit 1 divergences among closely related species. Proc. R. Soc. Lond. B 2003, 270, S96-S99. [CrossRef] [PubMed]

23. Hebert, P.D.N.; Stoeckle, M.Y.; Zemlak, T.S.; Francis, C.M. Identification of birds through DNA barcodes. PLoS Biol. 2004, 2, e312. [CrossRef] [PubMed]

24. Barth, D.; Krenek, S.; Fokin, S.I.; Berendonk, T.U. Intraspecific genetic variation in Paramecium revealed by mitochondrial cytochrome c oxidase I sequences. J. Eukaryot. Microbiol. 2006, 53, 20-25. [CrossRef] [PubMed]

25. Chantangsi, C.; Lynn, D.H. Phylogenetic relationships within the genus Tetrahymena inferred from the cytochrome c oxidase subunit 1 and the small subunit ribosomal RNA genes. Mol. Phylogenet. Evol. 2008, 49, 979-987. [CrossRef]

26. Chantangsi, C.; Lynn, D.H.; Brandl, M.T.; Cole, J.C.; Hetrick, N.; Ikonomi, P. Barcoding ciliates: A comprehensive study of 75 isolates of the genus Tetrahymena. Inter. J. Syst. Evol. Microbiol. 2007, 57, 2412-2425. [CrossRef]

27. Gentekaki, E.; Lynn, D.H. High-level genetic diversity but no population structure inferred from nuclear and mitochondrial markers of the peritrichous ciliate Carchesium polypinum in the Grand River Basin (North America). Appl. Environ. Microbiol. 2009, 75, 3187-3195. [CrossRef]

28. Jung, S.J.; Im, E.Y.; Strüder-Kypke, M.C.; Kitamura, S.I.; Woo, P.T.K. Small sub-unit ribosomal RNA and mitochondrial cytochrome c oxidase subunit 1 gene sequences of 21 strains of the parasitic scuticociliate Miamiensis avidus (Ciliophora, Scuticociliatia). Parasitol. Res. 2011, 108, 1153-1161. [CrossRef]

29. Kher, C.P.; Doerder, F.P.; Cooper, J.; Ikonomi, P.; Achilles-Day, U.; Kupper, F.C.; Lynn, D.H. Barcoding Tetrahymena: Discriminating species and identifying unknowns using the cytochrome c oxidase subunit I (cox1) barcode. Protist 2011, 162, 2-13. [CrossRef] [PubMed]

30. Tarcz, S.; Potekhin, A.; Rautian, M.; Przybos, E. Variation in ribosomal and mitochondrial DNA sequences demonstrates the existence of intraspecific groups in Paramecium multimicronucleatum (Ciliophora, Oligohymenophorea). Mol. Phylogenet. Evol. 2012, 63, 500-509. [CrossRef]

31. Tarcz, S.; Przybos, E.; Surmacz, M. An assessment of haplotype variation in ribosomal and mitochondrial DNA fragments suggests incomplete lineage sorting in some species of the Paramecium aurelia complex (Ciliophora, Protozoa). Mol. Phylogenet. Evol. 2013, 67, 255-265. [CrossRef]

32. Tarcz, S.; Rautian, M.; Potekhin, A.; Sawka, N.; Beliavskaya, A.; Kiselev, A.; Nekrasova, I.; Przybos, E. Paramecium putrinum (Ciliophora, Protozoa): The first insight into the variation of two DNA fragments-Molecular support for the existence of cryptic species. Mol. Phylogenet. Evol. 2014, 73, 140-145. [CrossRef]

33. Zhao, Y.; Gentekaki, E.; Yi, Z.; Lin, X. Genetic differentiation of the mitochondrial cytochrome oxidase c subunit I gene in genus Paramecium (Protista, Ciliophora). PLoS ONE 2013, 8, e77044. [CrossRef] [PubMed]

34. Zhao, Y.; Yi, Z.; Gentekaki, E.; Zhan, A.; Al-Farraj, S.A.; Song, W. Utility of combining morphological characters, nuclear and mitochondrial genes: An attempt to resolve the conflicts of species identification for ciliated protists. Mol. Phylogenet. Evol. 2016, 94, 718-729. [CrossRef] [PubMed]

35. Park, M.H.; Jung, J.H.; Jo, E.; Park, K.M.; Baek, Y.S.; Kim, S.J.; Min, G.S. Utility of mitochondrial CO1 sequences for species discrimination of Spirotrichea ciliates (Protozoa, Ciliophora). Mitochon. DNA Part A 2019, 30, 148-155. [CrossRef] [PubMed]

36. Strüder-Kypke, M.C.; Lynn, D.H. Comparative analysis of the mitochondrial cytochrome $c$ oxidase subunit I (COI) gene in ciliates (Alveolata, Ciliophora) and evaluation of its suitability as a biodiversity marker. Syst. Biodivers. 2010, 8, 131-148. [CrossRef]

37. Agamaliev, F.G. New species of psammobiotic ciliates of the western coast of the Caspian Sea. Acta Protozool. 1966, 4, 169-183.

38. Curds, C.R. Guide to the species of the genus Euplotes (Hypotrichida, Ciliatea). Bull. Bri. Mus. Nat. Hist. 1975, $28,3-61$.

39. Di Giuseppe, G.; Erra, F.; Frontini, F.P.; Dini, F.; Vallesi, A.; Luporini, P. Improved description of the bipolar ciliate, Euplotes petzi, and definition of its basal position in the Euplotes phylogenetic tree. Eur. J. Protistol. 2014, 50, 402-411. [CrossRef] 
40. Gao, Y.; Gong, R.; Jiang, Y.; Pan, B.; Li, Y.; Warren, A.; Jiang, J.; Gao, F. Morphogenetic characters of the model ciliate Euplotes vannus (Ciliophora, Spirotrichea): Notes on cortical pattern formation during conjugational and postconjugational reorganization. Eur. J. Protistol. 2020, 73, 125675. [CrossRef]

41. Hu, X.; Lin, X.; Song, W.B. Ciliate Atlas: Species Found in the South China Sea; Science Press: Beijing, China, 2019.

42. Kahl, A. Urtiere oder Protozoa I: Wimpertiere oder Ciliata (Infusoria) 3. Spirotricha. Tierwelt Dtl. 1932, 25, 399-650.

43. Lian, C.; Zhang, T.; Al-Rasheid, K.A.S.; Yu, Y.; Jiang, J.; Huang, J. Morphology and SSU rDNA-based phylogeny of two Euplotes species from China: E. wuhanensis sp. n. and E. muscicola Kahl, 1932 (Ciliophora, Euplotida). Eur. J. Protistol. 2019, 67, 1-14. [CrossRef]

44. Valbonesi, A.; Luporini, P. Description of two new species of Euplotes and Euplotes rariseta from Antarctica. Polar Biol. 1990, 11, 47-53. [CrossRef]

45. Williams, R.A.J.; Owens, H.L.; Clamp, J.; Peterson, A.T.; Warren, A.; Martín-Cereceda, M. Endemicity and climatic niche differentiation in three marine ciliated protists. Limnol. Oceanogr. 2018, 63, 2727-2736. [CrossRef]

46. Abraham, J.S.; Somasundaram, S.; Maurya, S.; Gupta, R.; Makhija, S.; Toteja, R. Characterization of Euplotes lynni nov. spec., E. indica nov. spec. and description of E. aediculatus and E. woodruffi (Ciliophora, Euplotidae) using an integrative approach. Eur. J. Protistol. 2021, 79, 125779. [CrossRef] [PubMed]

47. Jiang, J.; Zhang, Q.; Warren, A.; Al-Rasheid, K.A.S.; Song, W. Morphology and SSU rRNA gene-based phylogeny of two marine Euplotes species, E. orientalis spec. nov. and E. raikovi Agamaliev, 1966 (Ciliophora, Euplotida). Eur. J. Protistol. 2010, 46, 121-132. [CrossRef] [PubMed]

48. Lian, C.; Wang, Y.; Li, L.; Al-Rasheid, K.A.S.; Jiang, J.; Song, W. Taxonomy and SSU rDNA-based phylogeny of three new Euplotes species (Protozoa, Ciliophora) from China seas. J. King Saud Univ. Sci. 2020, 32, 1286-1292. [CrossRef]

49. Lian, C.; Wang, Y.; Jiang, J.; Yuan, Q.; Al-Farraj, S.A.; El-Serehy, H.A.; Song, W.; Stoeck, T.; Shao, C. Systematic positions and taxonomy of two new ciliates found in China: Euplotes tuffraui sp. nov. and E. shii sp. nov. (Alveolata, Ciliophora, Euplotida). Syst. Biodivers. 2021, 19, 359-374. [CrossRef]

50. Zhao, Y.; Yi, Z.; Warren, A.; Song, W. Species delimitation for the molecular taxonomy and ecology of a widely distributed microbial eukaryotes genus Euplotes (Alveolata, Ciliophora). Proceed. Roy. Soc. B 2018, 285, 20172159. [CrossRef] [PubMed]

51. Dunthorn, M.; Foissner, W.; Katz, L.A. Expanding character sampling for ciliate phylogenetic inference using mitochondrial SSU-rDNA as a molecular marker. Protist 2011, 162, 85-99. [CrossRef] [PubMed]

52. Foissner, W. An update of 'basic light and scanning electron microscopic methods for taxonomic studies of ciliated protozoa'. Int. J. Syst. Evol. Microbiol. 2014, 64, 271-292. [CrossRef] [PubMed]

53. Medlin, L.; Elwood, H.J.; Stickel, S.; Sogin, M.L. The characterization of enzymatically amplified eukaryotic 16S-like rRNA-coding regions. Gene 1988, 71, 491-499. [CrossRef]

54. Hall, T.A. BioEdit: A user-friendly biological sequence alignment editor an analysis program for Windows 95/98/ NT. Nucleic Acids Symp. Ser. 1999, 41, 95-98.

55. Librado, P.; Rozas, J. DnaSP v5: A software for comprehensive analysis of DNA polymorphism data. Bioinformatics 2009, 25, 1451-1452. [CrossRef] [PubMed]

56. Miller, M.A.; Pfeiffer, W.; Schwartz, T. Creating the CIPRES Science Gateway for inference of large phylogenetic trees. In Proceedings of the 2010 Gateway Computing Environments Workshop (GCE), New Orleans, LA, USA, 14 November 2010; pp. 1-8.

57. Stamatakis, A. RAxML version 8: A tool for phylogenetic analysis and post-analysis of large phylogenies. Bioinformatics 2014, 30, 1312-1313. [CrossRef] [PubMed]

58. Ronquist, F.; Teslenko, M.; van Der Mark, P.; Ayres, D.L.; Darling, A.; Höhna, S.; Larget, B.; Liu, L.; Suchard, M.A.; Huelsenbeck, J.P. MrBayes 3.2: Efficient Bayesian phylogenetic inference and model choice across a large model space. Syst. Biol. 2012, 61, 539-542. [CrossRef]

59. Nylander, J. MrModeltest, a Program to Evaluate the Fit of Several Models of Evolution to a Given Data and Unrooted Tree (Version 2.2). Program Distributed by the Author. Evolutionary Biology Centre, Uppsala University, Sweden. 2004. Available online: http:/ / www.abc.se/ \{\}nylander (accessed on 10 August 2021).

60. Tamura, K.; Peterson, D.; Peterson, N.; Stecher, G.; Nei, M.; Kumar, S. MEGA5: Molecular evolutionary genetics analysis using maximum likelihood, evolutionary distance, and maximum parsimony methods. Mol. Phylogenet. Evol. 2011, 28, 2731-2739. [CrossRef]

61. Chen, X.; Zhao, Y.; Al-Farraj, S.A.; Al-Quraishy, S.A.; El-Serehy, H.A.; Shao, C.; Al-Rasheid, K.A.S. Taxonomic descriptions of two marine ciliates, Euplotes dammamensis n. sp. and Euplotes balteatus (Dujardin, 1841) Kahl, 1932 (Ciliophora, Spirotrichea, Euplotida), collected from the Arabian Gulf, Saudi Arabia. Acta Protozool. 2013, 52, 73-89.

62. Petroni, G.; Dini, F.; Verni, F.; Rosati, G. A molecular approach to the tangled intrageneric relationships underlying phylogeny in Euplotes (Ciliophora, Spirotrichea). Mol. Phylo. Evol. 2002, 22, 118-130. [CrossRef]

63. Yi, Z.; Song, W.; Clamp, J.C.; Chen, Z.; Gao, S.; Zhang, Q. Reconsideration of systematic relationships within the order Euplotida (Protista, Ciliophora) using new sequences of the gene coding for small-subunit rRNA and testing the use of combined data sets to construct phylogenies of the Diophrys-complex. Mol. Phylogenet. Evol. 2009, 50, 599-607. [CrossRef]

64. Di Giuseppe, G.; Barbieri, M.; Vallesi, A.; Luporini, P.; Dini, F. Phylogeographical pattern of Euplotes nobilii, a protist ciliate with a bipolar biogeographical distribution. Mol. Ecol. 2013, 22, 4029-4037. [CrossRef] 
65. Fokin, S.I.; Przybos, E.; Chivilev, S.M.; Beier, C.L.; Horn, M.; Skotarczak, B.; Wodecka, B.; Fujishima, M. Morphological and molecular investigations of Paramecium schewiakoffi sp. nov. (Ciliophora, Oligohymenophorea) and current status of distribution and taxonomy of Paramecium spp. Eur. J. Protistol. 2004, 40, 225-243. [CrossRef]

66. Rand, D.M. The units of selection on mitochondrial DNA. Ann. Rev. Ecol. Syst. 2001, 32, 415-448. [CrossRef]

67. Beijerinck, M.W. De Infusies en de Ontdekking der Backteriën; Müller: Amsterdam, The Netherlands, 1913.

68. Finlay, B.J.; Corliss, J.O.; Esteban, G.; Fenchel, T. Biodiversity at the microbial level: The number of free-living ciliates in the biosphere. Q. Rev. Biol. 1996, 71, 221-237. [CrossRef]

69. Foissner, W. Protist diversity: Estimates of the near-imponderable. Protist 1999, 150, 363-368. [CrossRef]

70. Fontaneto, D.; Barraclough, T.G.; Chen, K.; Ricci, C.; Herniou, E.A. Molecular evidence for broadscale distributions in bdelloid rotifers: Everything is not everywhere but most things are very widespread. Mol. Ecol. 2008, 17, 3136-3146. [CrossRef] [PubMed] 